\title{
Effect of Structural Parameters and Materials on the Mechanical Characteristics of Expansion Tube
}

\author{
Zizhen Qi, Yuwu Zhang, and Yuliang Lin* \\ College of Liberal Arts and Science, National University of Defense Technology, Changsha, Hunan 410073, \\ China; zizhenqi@foxmail.com (Z.Q.); zhangyuwu12@nudt.edu.cn (Y.Z.) \\ * Correspondence: ansen_liang@163.com; Tel.: +86-138-0848-4146
}

\begin{abstract}
Expansion tube is ideal energy absorber which dissipates kinetic energy through plastic deformation and friction. There is an urgent need to understand the influence of key parameter, e.g. semi angle, tube material, and friction coefficient, on the mechanical response and energy absorption characteristics of expansion tube. In the present work, the material properties of the tubes were tested under quasi-static loading condition, and the numerical simulations were carried out by using commercial software ABAQUS. Based on the validated finite element simulation, all the semi angle, tube material, and friction have significant effects on the energy absorption capacity of expansion tube. The expansion tube with high tensile stress of parent material have high energy absorption capacity, while the specific energy absorption is linear with the tensile stress/density of tube material. This work would give a guidance to the structural design and parent materials selection for expansion tubes.
\end{abstract}

Keywords: expansion tube; mechanical properties; energy absorption; parent material comparison; plastic deformation.

\section{Introduction}

Tubular energy absorbers are promising energy absorption structure, and have drawn more and more attention in the field of energy absorption device design [1-7]. Researches have carried numerous studies on the circular tubes and square tubes. The failure modes of tubular energy absorbers can be divided into the following types: buckling [8,9], tearing $[2,10,11]$, expansion $[12$, 13]. As shown in Figure 1, when a load is transmitted to the expansion tube, the cone piston is compressed into the tube [14]. As the diameter of cone piston is larger than the inner diameter of the tube, the tube gives rise to elastic and plastic deformation under the compression of cone piston. In addition, the expansion tube enables to absorb energy through frictional dissipation between cone piston and inner wall of the tube. Due to the homogeneous deformation mechanism [14, 15], constant expansion force [16], irreversible plastic deformation [17, 18], light weight and high energy absorption capacity [19], expansion tubes have been frequently applied in many important fields in recent years [18, 20], e.g. aircraft, aerospace, transportation and building, which are involved in cushioning. 


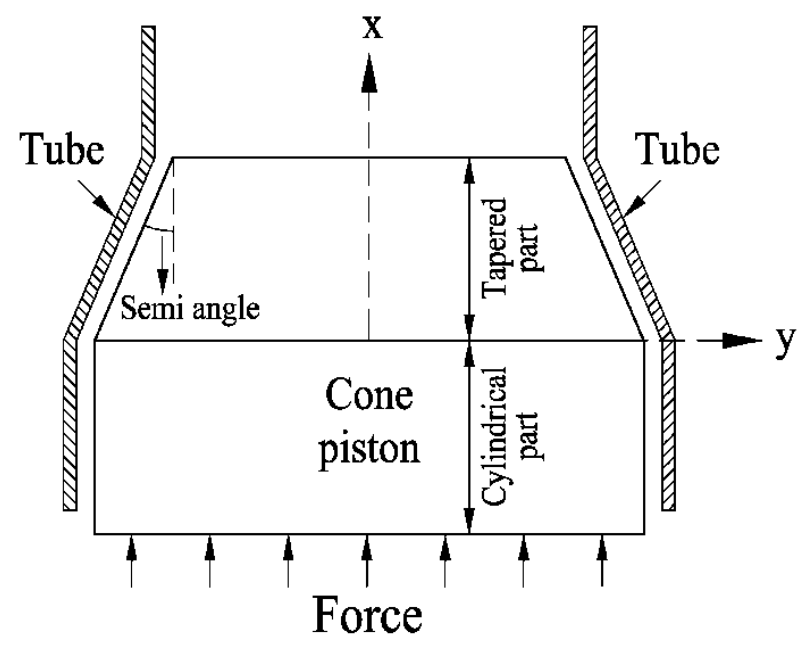

Figure 1. Schematic sketch of expansion tube.

By means of experiment, numerical simulation and theoretical analysis, previous researches have widely evaluated the effects of key parameters on the mechanical properties of expansion tubes. Yang et al. [16] reported the plastic energy absorption behavior of expansion tubes under axial compression by means of experiment and numerical simulation. They discussed the characteristics of the expansion force-displacement curves in different deformation modes. Fischer et al. [21] presented analytical expressions for the stress, strain fields and the stable-state expansion force. Additionally, they proposed a rigid-perfectly plastic material model where a linear function was used to approximate the wall thickness within the deformed region of the tubes. By means of numerical simulation and theoretical analysis, Yan et al. [18] reported the energy absorption behavior of expansion tubes. They found that the relationship between the semi angle and the stable expansion force is nonlinear, while that of the friction coefficient and the stable expansion force is linear. Additionally, taking into consideration the additional shear deformation and expansion ratio enlargement, they presented a theoretical prediction model. Choi et al. [13] reported energy absorption characteristics of expansion tubes under dynamic impact. The numerical simulation and least square method were introduced to calculate the friction coefficient under different impact velocities. Choi et al. [12] reported the mechanical response and energy absorption characteristics of expansion tubes with different semi angles, and they found that the semi angles were inversely proportional to the shear friction factor. Alves et al. [22, 23] reported the end forming of thin-walled tubes and the influence of material flow. It indicates that, to avoid structural failure, i.e. ductile fracture, local buckling and wrinkling, the diameter, wall thickness, shape and length of the expansion tubes as well as lubrication regime should be properly selected.

The semi angle has a considerable influence on the mechanical response and energy absorption characteristics of expansion tube [12]. However, in the published articles, there is no systematic study about the effect of semi angle which can be varied via changing the diameter of cylindrical part and length of tapered part. In addition, the tube material is also important in influencing the mechanical response of expansion tube. Previous researchers used steel or aluminum as tube material to study mechanical response of expansion tube. However, the relationship between tube material and mechanical characteristics has not been built. Hence, these researches cannot guide the design of expansion tube well. This work focus on the influence of semi angle, tube material, as well as friction coefficient on the mechanical response, energy absorption characteristics of expansion tubes by means of numerical simulation and experiment [24, 25]. The layout of the rest of the paper is arranged as follows. In section 2, the material properties of tube is tested and the finite element models of expansion tubes were created. In section 3, experiments were carried out, and the effect of semi angle, tube material, and friction coefficient (between the tube and cone piston) on the mechanical characteristics [26] of expansion tube are discussed, followed by a conclusion in Section 4 . This work enables the improvement of structural design and selection of parent materials of expansion tubes. 


\section{Material Properties Test and Finite Element Simulation}

\subsection{Material Properties Test}

The tubes investigated were made of 1060/O aluminum. As shown in Figure 2, to identify the mechanical properties of tubes, the standard tensile tests were conducted on the parent material at a constant strain rate of $5.0 \times 10^{-3} \mathrm{~s}^{-1}$ using a WDW-500E universal test machine. The tensile sample is designed with reference to the National Standard GB/T228.1-2010 of China. The thickness, width of middle part, gauge length of the tensile sample are $3 \mathrm{~mm}, 8 \mathrm{~mm}, 45 \mathrm{~mm}$, respectively. It is found that the true stress-strain curves of parent material for the repeated tests were similar, and the true stressstrain curve of their average value is shown in Figure 3.
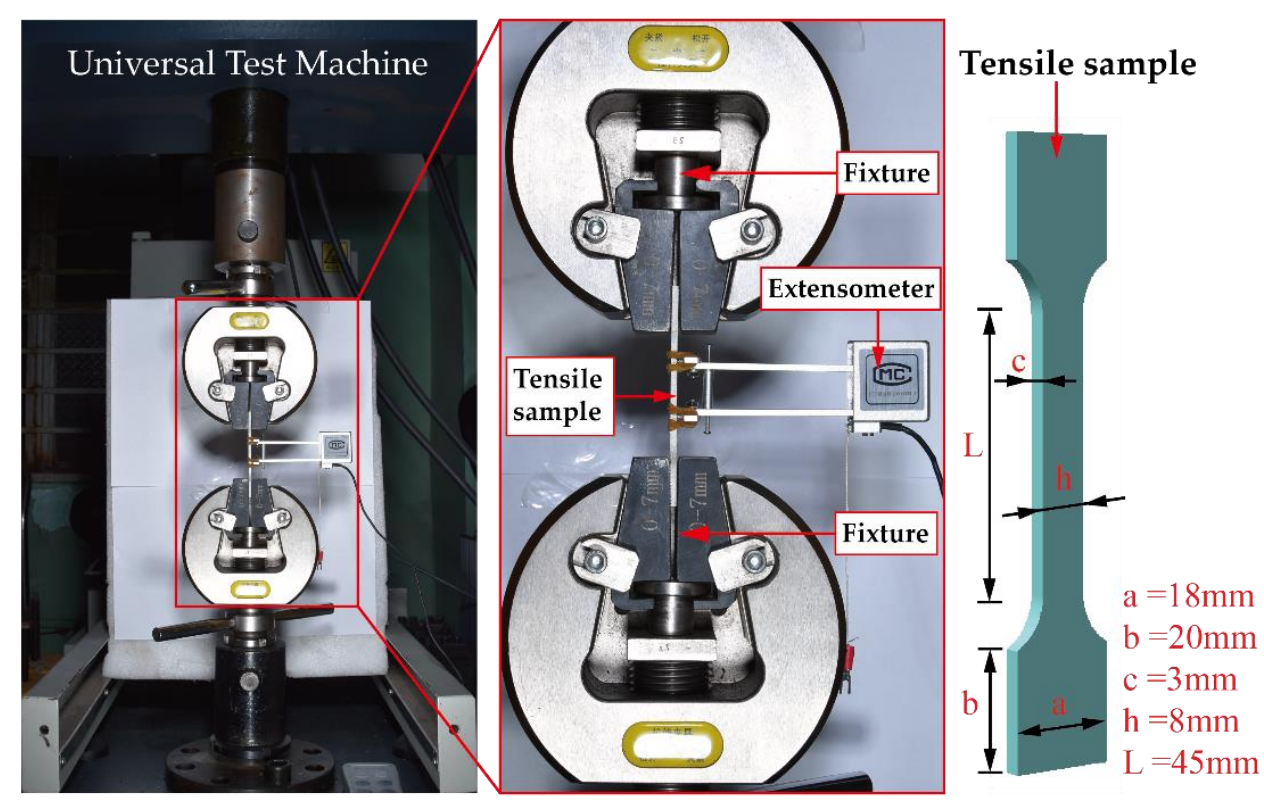

Figure 2. Standard tensile test setup for parent material of expansion tube.

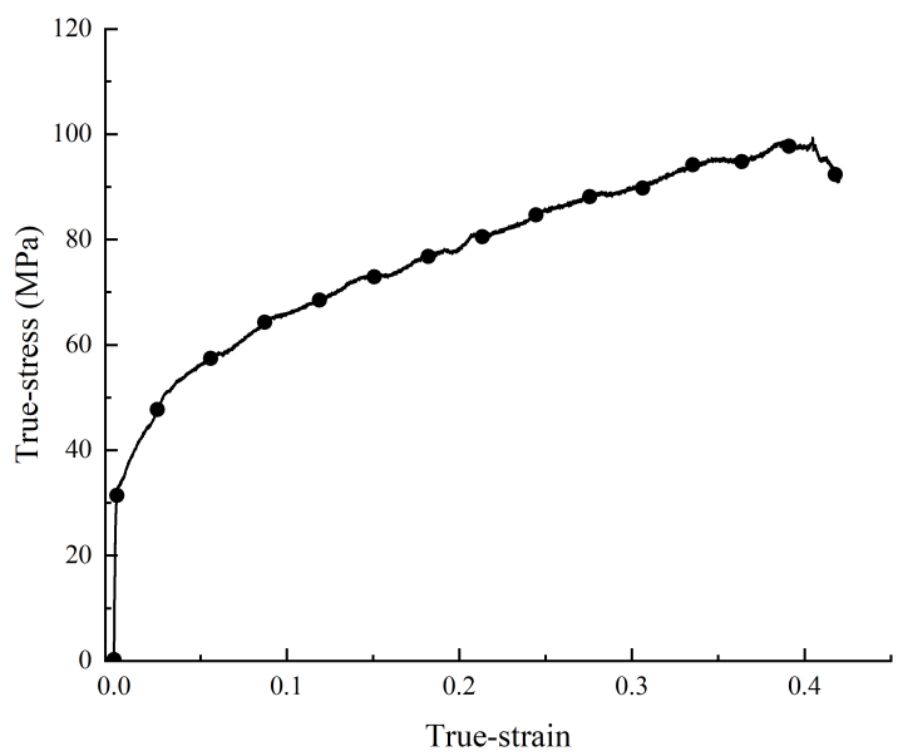

Figure 3. Average true tensile stress-strain curve for 1060/O aluminum.

\subsection{Finite Element Simulation}




\subsubsection{Constitutive models and material parameters}

Based on the curve shown in Figure 3, the $0.2 \%$ proof stress $\sigma 0.2$, tensile stress $\sigma_{\mathrm{b}}$ and elastic modulus $E$ of $1060 / \mathrm{O}$ aluminum can be obtained as $31.8 \mathrm{MPa}, 98.2 \mathrm{MPa}$, and $69.2 \mathrm{GPa}$, respectively. The density $\rho$ and Poisson's ratio $v$ of the $1060 / \mathrm{O}$ aluminum are $2.7 \mathrm{~g} / \mathrm{cm}^{3}$ and 0.33 , respectively. The shear damage criterion was adopted in simulation and the fracture strain $\varepsilon$ P was set to be 0.42 . The material used for the cone pistons was AISI 304 steel (0Cr18Ni9) with $0.2 \%$ proof stress $\sigma_{0.2}$ of 207 $\mathrm{MPa}$, tensile stress $\sigma_{\mathrm{b}}$ of $517 \mathrm{MPa}$, elastic modulus $E$ of $190 \mathrm{GPa}$, density $\rho$ of $8.0 \mathrm{~g} / \mathrm{cm}^{3}$ and Poisson's ratio $v$ of 0.29 . All the parameters of the material constitutive model for the tube and the cone piston have been listed in Table 1. Due to the strength of the cone piston is much higher than the strength of the tube, the cone piston can be regarded as rigid.

Table 1. Parameters of material constitutive model for expansion tube.

\begin{tabular}{clcc}
\hline Part & Parameter & Symbol & Values \\
\hline Tube & 0.2\% proof stress $(\mathrm{MPa})$ & $\sigma_{0.2}$ & 31.8 \\
& Tensile stress $(\mathrm{MPa})$ & $\sigma_{\mathrm{b}}$ & 98.2 \\
& Elastic modulus $(\mathrm{GPa})$ & $E$ & 69.2 \\
& Density $\left(\mathrm{g} / \mathrm{cm}^{3}\right)$ & $\rho$ & 2.7 \\
& Poisson's ratio & $v$ & 0.33 \\
& fracture strain & $\varepsilon \mathrm{P}$ & 0.42 \\
Cone piston & 0.2\% proof stress $(\mathrm{MPa})$ & $\sigma_{0.2}$ & 207 \\
& Tensile stress $(\mathrm{MPa})$ & $\sigma_{\mathrm{b}}$ & 517 \\
& Elastic modulus $(\mathrm{GPa})$ & $E$ & 190 \\
& Density (g/cm $\left.{ }^{3}\right)$ & $\rho$ & 8.0 \\
& Poisson's ratio & $v$ & 0.29 \\
Surface-to- & Friction coefficient & $f$ & 0.17 \\
\hline
\end{tabular}

The expansion tube dissipates energy through plastic deformation and friction. In order to avoid adhesive wear, the molybdenum disulfide grease was used between the tube and the cone piston in the experiments. The friction coefficient $f=0.17$ was gained by comparing the experimental results with the simulated results.

\subsubsection{Finite element simulation}

A finite element model of the expansion tube was modeled to simulated the mechanical response of the tube expansion using the commercial finite element package ABAQUS [27]. As shown in Figure 4 , an axisymmetric model (only half of the cross section of the expansion tube) was built because of the structural axisymmetric. The tube and cone piston were modeled with 4-node 2D bilinear axisymmetric quadrilateral elements (CAX4R in ABAQUS notion) with reduced integration. According to the convergence analysis, the elements number in wall thickness of the tube is adopted to be 4 , which was adequate for simulating the major field variables distribution. Additionally, the element size of the cone piston is adopted to be $1 \mathrm{~mm}$. The left end of the tube was tied with a rigid plate and there was no displacement in $\mathrm{x}$-direction and $\mathrm{y}$-direction. The right end of the tube was compressed by the cone piston in $\mathrm{x}$ direction under quasi-static loading condition, and the cone piston stopped moving when its displacement reached $50 \mathrm{~mm}$. The surface-to-surface contact algorithm was activated in the model, and a reference point (named RP) was set at the rigid plate to record the expansion force-time history. 


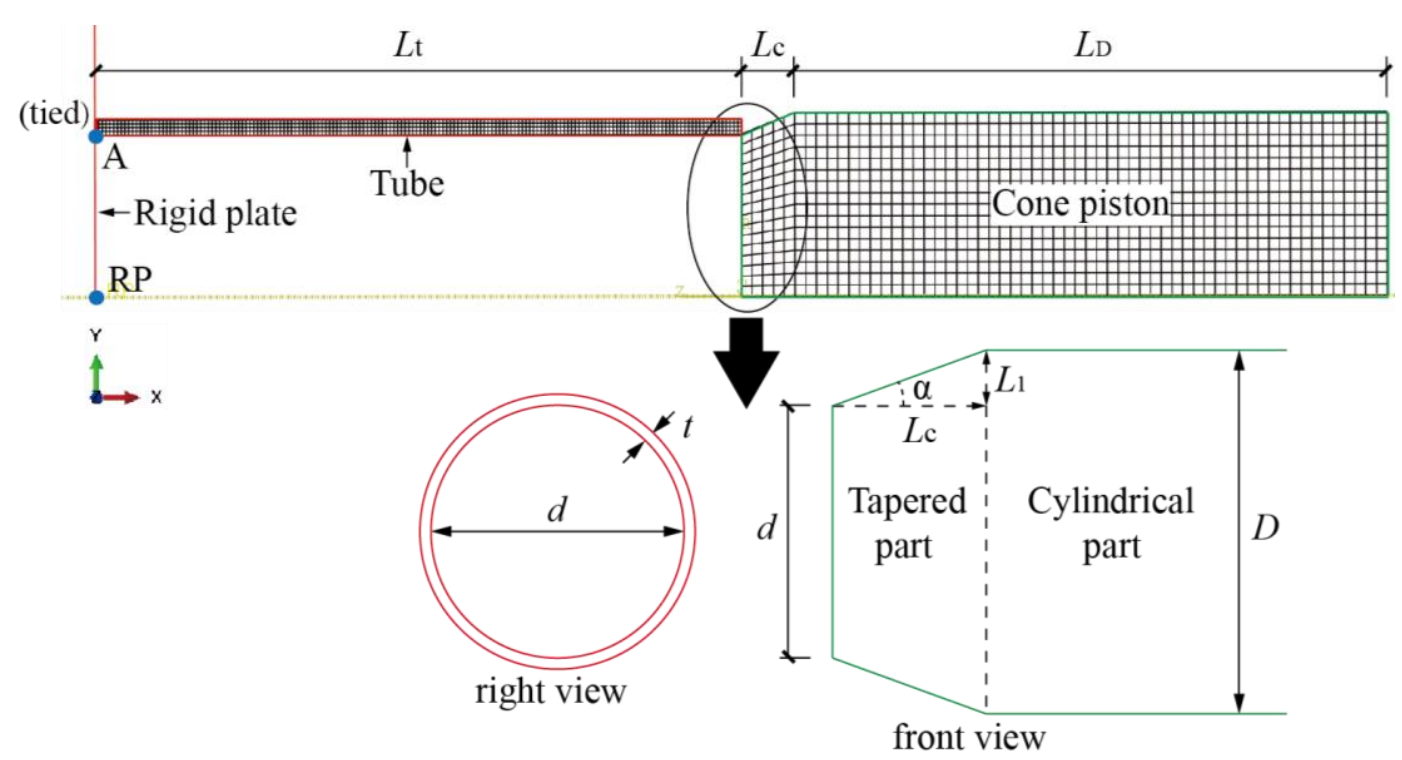

Figure 4. Finite element model for numerical analysis.

In the simulation, the structural parameters of the tubes are fixed, that is, the tube inner diameter $d=30 \mathrm{~mm}$; the wall thickness $t=1.4 \mathrm{~mm}$. Additionally, to obtain a steady-state expansion force and dissipate the influence of the fixed boundary [28], the axial length of the tube is taken as $L_{\mathrm{t}}=60 \mathrm{~mm}$. As shown in Figure 4, the cone piston can be divided into two parts: the tapered part and the cylindrical part. The diameter of the left end of the cone piston is equal to the inner diameter of the tube. The length of the cylindrical part is fixed as $L D=55 \mathrm{~mm}$. The length $L_{\mathrm{c}}$ of the tapered part varies from each other in different tests, so does the diameter $D$ of the cylindrical part. The semi angle $\alpha$ of the cone piston is defined as:

$$
\alpha=\cot \left(\frac{L_{1}}{L_{c}}\right)=\cot \left(\frac{D-d}{2 L_{c}}\right)
$$

It can be seen from Equation (1) that when the value of the inner diameter of the tube is fixed, there are two factors that affect the semi angle: the length $L_{c}$ of the tapered part and the diameter $D$ of the cylindrical part. As indicated in Figure 5(a), the cone piston maintained the same length of the tapered part, the semi angle increased as the diameter of the cylindrical part increased. When the cone piston maintained the same diameter of the cylindrical part, the semi angle decreased as the length of the tapered part increased, as shown in Figure 5(b). The semi angles of cone pistons in this study were $\alpha=3.82^{\circ} \sim 45^{\circ}$, and detailed dimensions of the cone pistons in different simulations are listed in Table 2. 


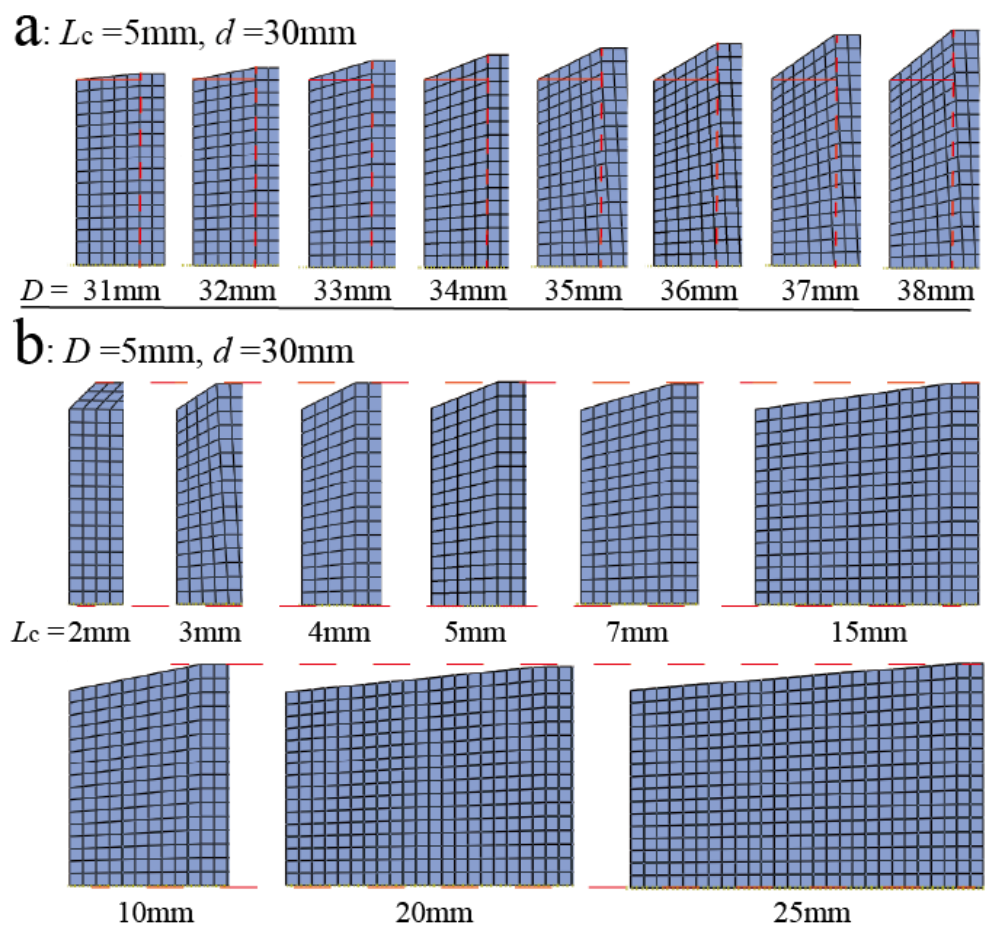

Figure 5. Cone pistons with different: (a) diameter $D$ of cylindrical part, and (b) length $L_{c}$ of tapered part.

Table 2. Summary of the dimensions of the cone piston.

\begin{tabular}{lcccc}
\hline Test NO. & $\left.\boldsymbol{L}_{\mathbf{c}} \mathbf{( m m}\right)$ & $\boldsymbol{D} \mathbf{( m m )}$ & $\mathbf{L}_{\mathbf{1}}(\mathbf{m m})$ & $\boldsymbol{\alpha} \mathbf{(}^{\circ}$ \\
\hline Test A01 & & 31 & 0.5 & 5.71 \\
Test A02 & & 32 & 1.0 & 11.31 \\
Test A03 & & 33 & 1.5 & 16.70 \\
Test A04 & 5 & 34 & 2.0 & 21.80 \\
Test A05 & & 35 & 2.5 & 26.57 \\
Test A06 & & 36 & 3.0 & 30.96 \\
Test A07 & & 37 & 3.5 & 34.99 \\
Test A08 & & 38 & 4.0 & 38.66 \\
Test B01 & 2 & & & 45 \\
Test B02 & 3 & & & 33.70 \\
Test B03 & 4 & & & 26.57 \\
Test B04 & 5 & & & 21.80 \\
Test B05 & 7 & & & 15.96 \\
Test B06 & 10 & 34 & 2.0 & 11.31 \\
Test B07 & 15 & & & 7.58 \\
Test B08 & 20 & & & 5.71 \\
Test B09 & 25 & & & 4.57 \\
Test B10 & 30 & & & 3.82 \\
\hline
\end{tabular}

In the numerical simulation, a specific expansion tube with $\alpha=21.80^{\circ}, L_{c}=5 \mathrm{~mm}, D=34 \mathrm{~mm}$ was selected to study the influence of the friction coefficient and tube materials on the mechanical properties and energy absorption characteristics of expansion tube. In addition to the friction coefficient of 0.17 , nine more friction coefficients were selected to carry out the study, ranging from 0 to 0.35 ; In addition to 1060/O aluminum, three more materials (6061/T6 aluminum, S20C steel, S45C steel) were selected as the parent material for the tube. The true tensile stress-strain curves of these 
three materials are shown in Figure 6, and their constitutive models are listed in Table 3. The friction coefficients and materials used in different simulations are listed in Table 4.

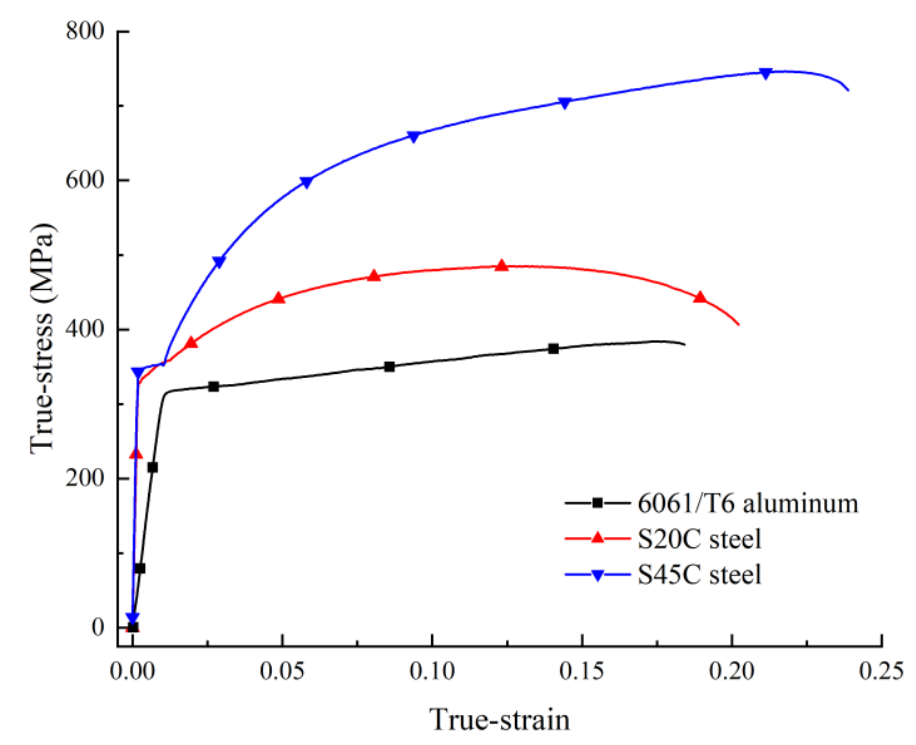

Figure 6. True tensile stress-strain curve for three materials.

Table 3. Parameters of constitutive model for three materials.

\begin{tabular}{lcccccc}
\hline Material & $\begin{array}{c}\text { Density } \\
\left(\mathbf{g} / \mathbf{c m}^{\mathbf{3}}\right)\end{array}$ & $\begin{array}{c}\text { Yeild stress } \\
(\mathbf{M P a})\end{array}$ & $\begin{array}{c}\text { Tensile } \\
\text { stress } \mathbf{( M P a})\end{array}$ & $\begin{array}{c}\text { Elastic modulus } \\
(\mathbf{G P a})\end{array}$ & $\begin{array}{c}\text { Poisson's } \\
\text { ratio }\end{array}$ & $\begin{array}{c}\text { fracture } \\
\text { strain }\end{array}$ \\
\hline 6061/T6 Al & 2.7 & 307.5 & 384.1 & 69 & 0.33 & 0.184 \\
S20C steel & 7.85 & 325.8 & 484.9 & 210 & 0.28 & 0.202 \\
S45C steel & 7.85 & 345.7 & 779.8 & 210 & 0.28 & 0.239 \\
\hline
\end{tabular}

Table 4. Summary of the friction coefficients and materials in different simulations.

\begin{tabular}{lccc}
\hline Test no. & Expansion tube & $\begin{array}{c}\text { Friction } \\
\text { coefficient }\end{array}$ & Material \\
\hline Test C01 & & 0 & \\
Test C02 & & 0.04 & \\
Test C03 & & 0.08 & \\
Test C04 & & 0.11 & \\
Test C05 & $\alpha=21.80^{\circ}$, & 0.14 & $1060 / \mathrm{O}$ aluminum \\
Test C06 & $L_{\mathrm{c}}=5 \mathrm{~mm}$, & 0.20 & \\
Test C07 & $D=34 \mathrm{~mm}$ & 0.25 & \\
Test C08 & & 0.30 & \\
Test C09 & & 0.35 & \\
Test D01 & & & 6061/T6 aluminum \\
Test D02 & & 0.17 & S20C steel \\
Test D03 & & & S45C steel \\
\hline
\end{tabular}

\section{Results and Discussion}

\subsection{FE Model Validation}


To validate the numerical finite model of the expansion tube, the expansion tubes with $\alpha=21.80^{\circ}$ $\left(L_{c}=5 \mathrm{~mm}, D=34 \mathrm{~mm}\right)$ were selected for the diameter expansion experiments. The shape and other structural parameters of the expansion tube were the same as the data mentioned above. The experiments were conducted on a WDW-500E universal test machine, as shown in Figure 7. Considering the actual situation of the experiments, a guide rail was added at the left end of the cone piston making it convenient for installation, as shown in Figure 8(c). Before the test, the expansion tube was adjusted to make the tube, cone piston and the test machine coaxial. The molybdenum disulfide grease was used between the tube and the cone piston. The cone piston was compressed into the tube by the cross-head of the test machine at a constant speed of $5 \mathrm{~mm} / \mathrm{min}$. The loaddisplacement curves were recorded by the test machine and the expansion process was recorded by a camera. To assess the local strain of the tube, digital image correlation (DIC) technology was used and speckles were sprayed on the tube surface $[20,29,30]$.

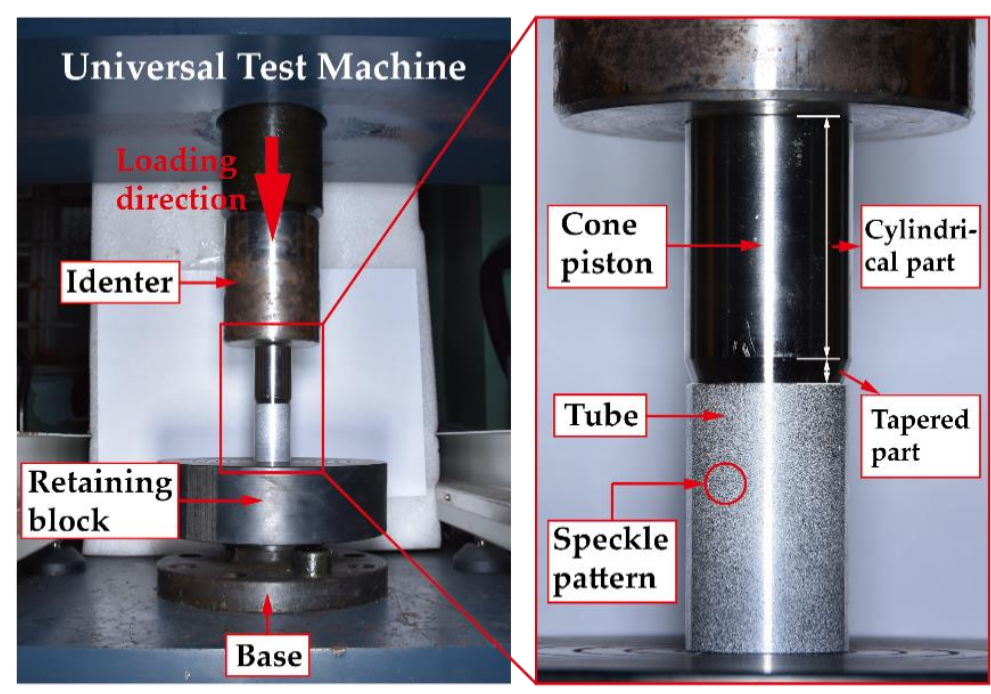

Figure 7. Setup of quasi-static experiment.

Figure 8 displays the strain field $\varepsilon_{\times}$(Figure $8(\mathrm{~b})$ ) from the DIC as well as deformed geometries (Figure 8(a), (c)) from the experiment and simulation at four representative stages: $S=5 \mathrm{~mm}, S=10 \mathrm{~mm}$, $S=15 \mathrm{~mm}$, and $S=30 \mathrm{~mm}$, where $S$ represents the displacement of cone piston. As shown in Figure 8(a), the expanded end of the tube rebounds to its mandrel, which is the same as that in numerical simulation. Figure 9 shows the experimentally measured and numerically predicted expansion forcedisplacement curves of expansion tubes under quasi-static loading condition. The experimental stable-state expansion force is consistent with the predicted stable-state expansion force, as shown in Figure 9. From the repeated experimental tests, it can be concluded that the expansion tubes have an ordered and stable deformation mode. Hence, the experimental and simulated strain field distributions as well as the response of tube maintain consistency. 


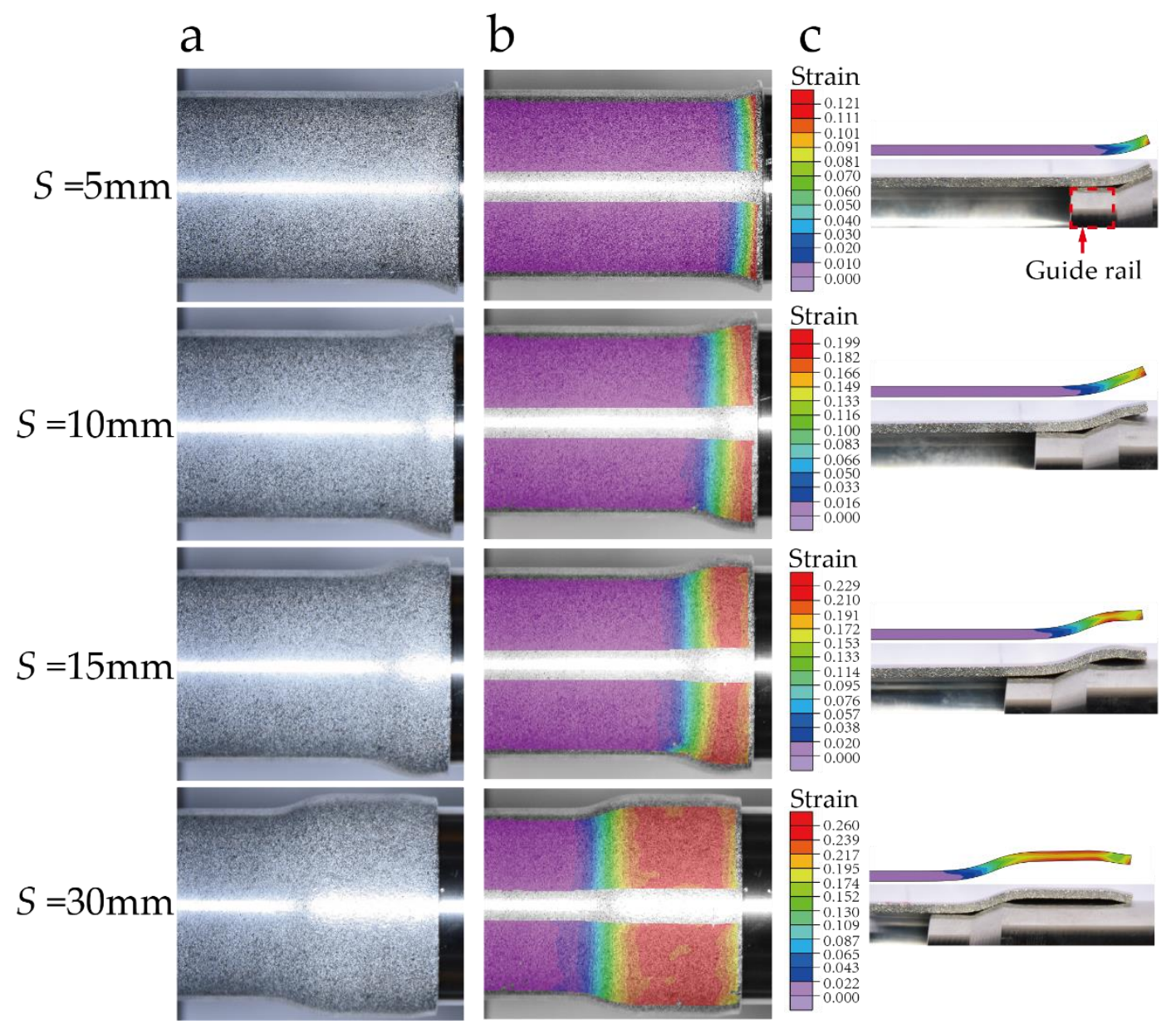

Figure 8. Comparison for a representative test of expansion tube $\left(\alpha=21.80^{\circ}, L_{\mathrm{c}}=5 \mathrm{~mm}, D=34 \mathrm{~mm}\right)$ : (a) images of deformed tube from test, (b) the field of strain $\varepsilon_{x}$ from DIC and (c) the field of strain $\varepsilon_{x}$ of the tube from numerical simulation.

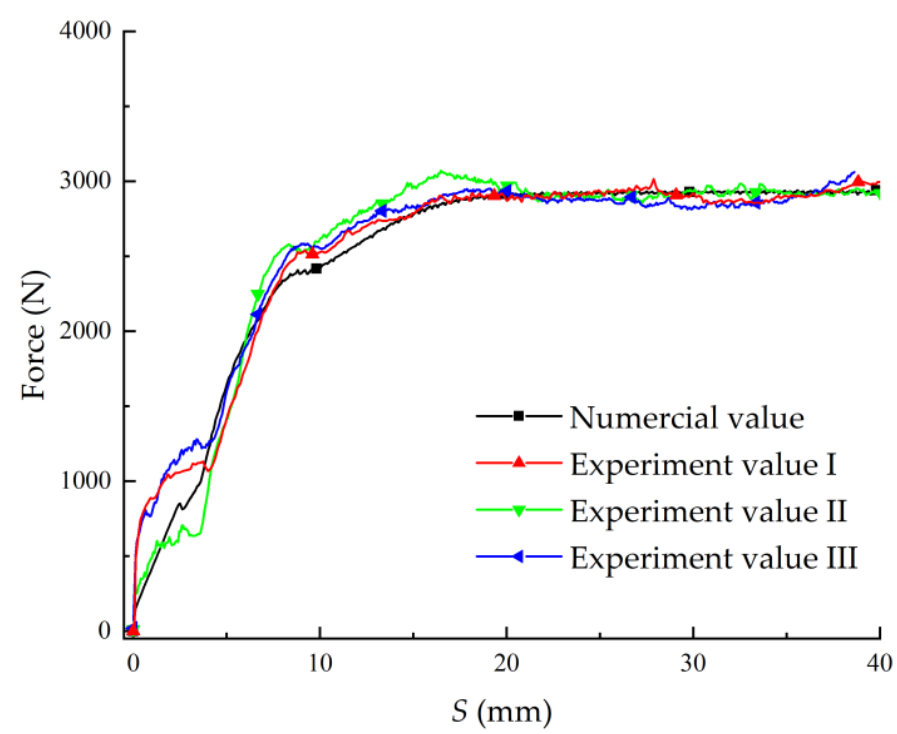

Figure 9. Comparison between numerical simulation and repeated experimental measurements.

\subsection{Mechanical Properties and Energy Absorption Characteristics of Expansion Tubes}

Based on the numerical results, this article will be discussed in terms of the following three aspects: the effect of cone piston's semi angle, the effect of tube material, as well as the effect of friction coefficient. 


\subsubsection{Effect of semi angle of the cone piston}

The predicted deformation process and the stress field distribution of the expansion tube $(\alpha$ $=21.80^{\circ}, L_{c}=5 \mathrm{~mm}, D=34 \mathrm{~mm}$ ) acquired from the output file are shown in Figure 10. The tube was expanded while the cone piston was initially compressed into the tube (seen Figure 10(b)). After the tapered part of the cone piston completely entered into the tube, the tube continued to expand radially outward due to its bending rigidity [16] (seen Figure 10(c)). With the increase of the displacement of the cone piston, the tube cannot continue to expand and starts to rebound because no pressure loaded on its inner wall (seen Figure 10(d)). After the above stages, the tube was kept at a stable state (seen Figure 10(e), (f)). According to Figure 10(c), the stress of the expanded tube has exceeded the yield stress of tube material (see Figure 3), suggesting that the irreversible plastic deformation occurs. Additionally, combined the strain field of tube shown in Figure 8 with the fracture strain shown in Figure 3, it can be concluded that the tube did not crack during expansion.

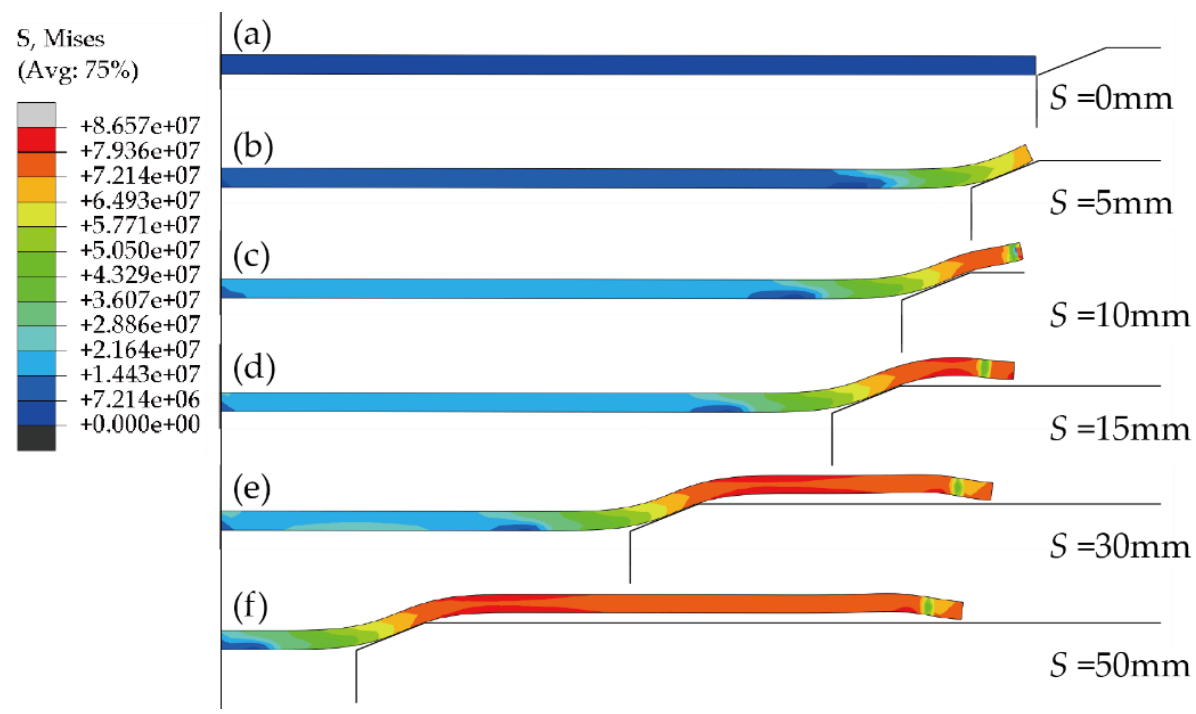

Figure 10. Deformation process and stress field distribution of a typical expansion tube $\left(\alpha=21.80^{\circ}, L_{\mathrm{c}}\right.$ $=5 \mathrm{~mm}, D=34 \mathrm{~mm}$ ) at six stages: (a) $S=0 \mathrm{~mm}$; (b) $S=5 \mathrm{~mm}$; (c) $S=10 \mathrm{~mm}$; (d) $S=15 \mathrm{~mm}$; (e) $S=30 \mathrm{~mm}$; (f) $S=50 \mathrm{~mm}$ of expansion. $S$ represents the displacement of the cone piston during the tube expansion process.

The expansion force-displacement curves under quasi-static loading condition, obtained from the output files are shown in Figure 11. All the expansion force-displacement curves can be divided into two parts, i.e. oscillation-stage and stable-stage. Oscillation-stage corresponding to the stage of expansion force increased and stable-stage corresponding to the stage of expansion force constant. For example, "I" and "II" represent the oscillation-stage and stable stage, respectively, for the expansion tube with $\alpha=5.71^{\circ}$, as shown in Figure 11(a). After the curves reaches the stable-stage II, the expansion force is quite stable, which is called stable-state expansion force (named $F_{\mathrm{s}}$ ). As shown in Figure 11(a), the trends of expansion force-displacement curves for the tubes with different semi angles are similar. However, as shown in Figure 11(b), due to the changes in the length $L_{c}$ of the tapered part, the displacements of cone piston varies when the expansion force reaches the stablestage. The expansion force-displacement curve has large fluctuations at the oscillation-stage when the tube is expanded by the cone piston with a large semi angle, whereas the expansion force increases steadily at the oscillation-stage when the tube is expanded by the cone piston with a small semi angle. The stable-state expansion force-semi angle curves of the expansion tubes are shown in Figure 12. As shown in Figure 11(a) and Figure 12, when the diameter $D$ of the cylindrical part increases and the length $L_{\mathrm{c}}$ of the tapered part keeps constant, the semi angle $\alpha$ increases, causing the stable-state expansion force to increase. As shown in Figure 11(b) and Figure 12, when the diameter $D$ of the cylindrical part remains unchanged and the length $L_{c}$ of the tapered part increases, the semi angle $\alpha$ decreases, causing the stable-state expansion force to decrease first and then increase. 
Furthermore, when the semi angle $\alpha$ is between $11.31^{\circ}$ and $21.80^{\circ}$, there exists a minimum stablestate expansion force $F_{s}$.

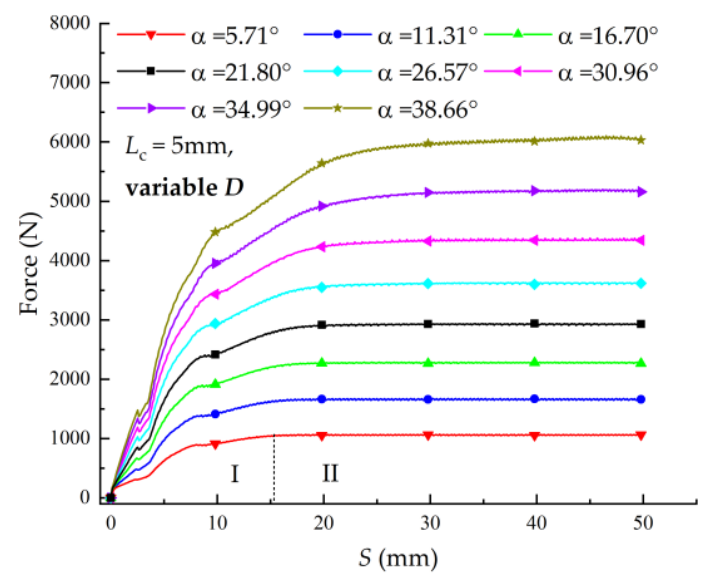

(a)

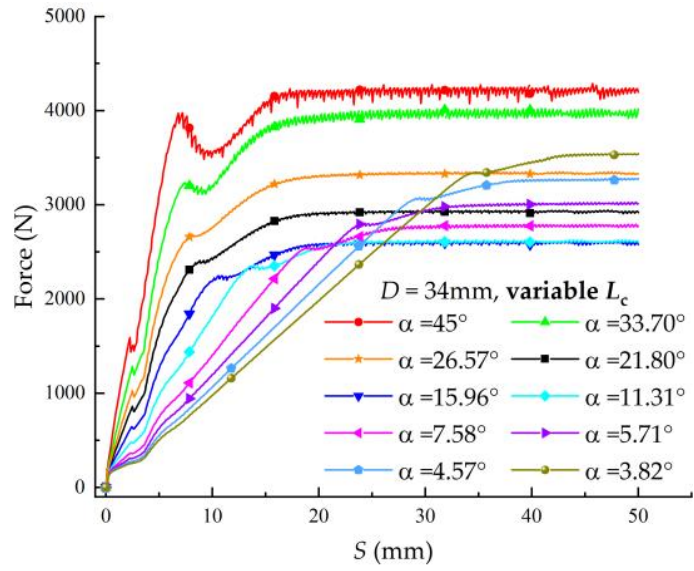

(b)

Figure 11. Simulated expansion force-displacement curves of cone piston with different semi angles $\alpha$ owing to: (a) variable diameter $D$ of the cylindrical part; (b) variable length $L_{\mathrm{c}}$ of the tapered part.

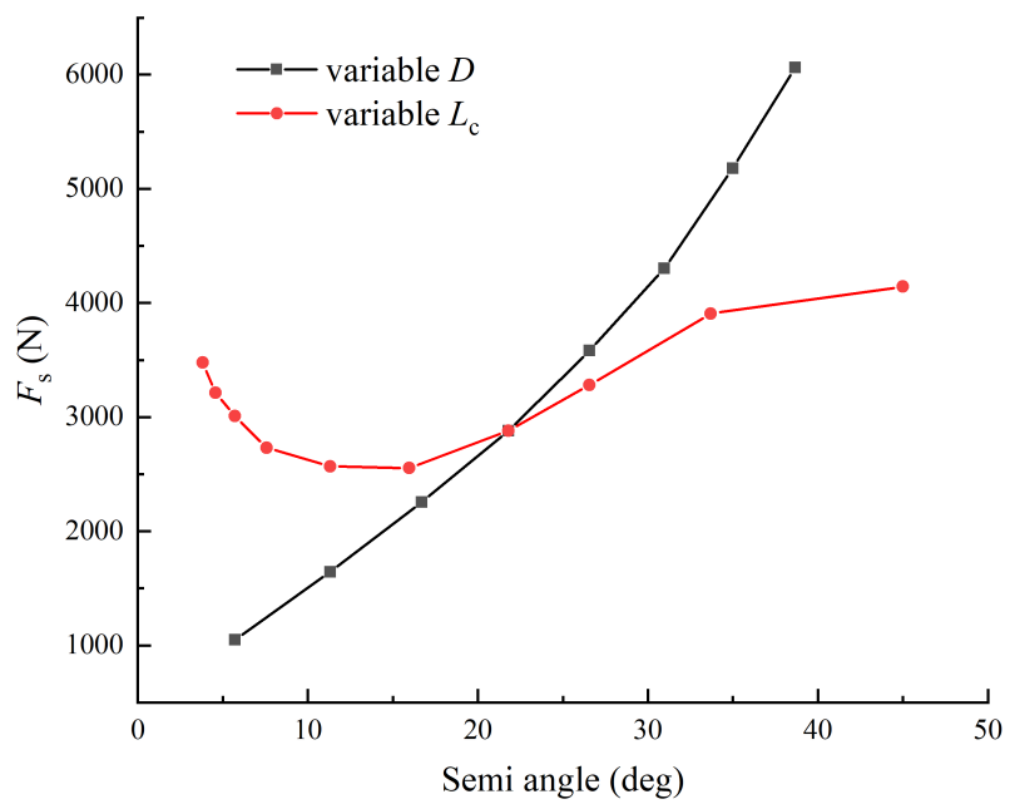

Figure 12. Stable-state expansion force-semi angle curves of expansion tubes with different diameters $D$ of cylindrical part and lengths $L_{c}$ of papered part of the cone pistons.

As illustrated in Figure 11 and Figure 12, the semi angle $\alpha$ increases with the increase of the diameter $D$ of the cylindrical part, causing the increase of stable-state expansion force. It should be noted that the semi angle decreases with the increase of the length $L_{\mathrm{c}}$ of tapered part, leading to the stable-state expansion force decreases first and then increases. This is contributed by two main factors, i.e. plastic deformation and friction dissipation. On one hand, the plastic deformation is reduced with the decrease of semi angle, which can be observed from the gap between expanded tube and cylindrical part of cone piston in Figure 13. On the other hand, as the semi angle continues to decrease, the contact area between cone piston and the tube increase, resulting in the expansion force caused by frictional dissipation increase. Hence, these two factors take different proportions in influencing the expansion force at different semi angles. 


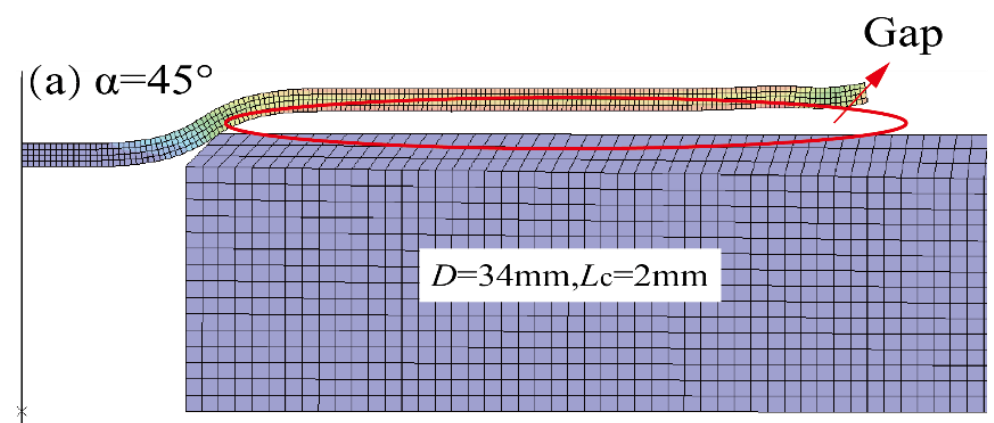

(b) $\alpha=21.8^{\circ}$

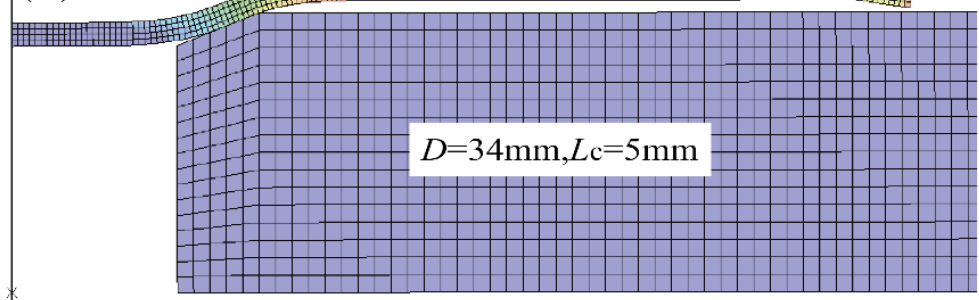

(c) $\alpha=7.58^{\circ}$

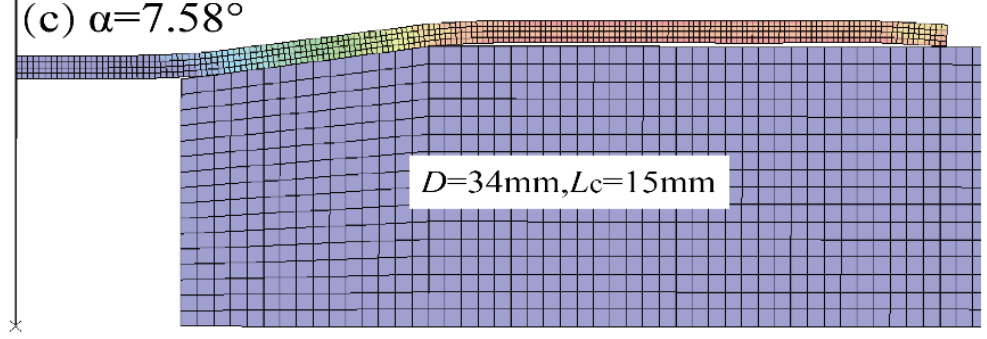

Figure 13. Expanded tubes shown on their respective semi angles: (a) $\alpha=45^{\circ}$, (b) $\alpha=21.8^{\circ}$, (c) $\alpha=$ $7.58^{\circ}$.

For cases of $D=34 \mathrm{~mm}, S=50 \mathrm{~mm}$, Figure 14 plots the deformed configurations of the tube inner wall for semi angle $\alpha$ ranging from $3.82^{\circ}$ to $45^{\circ}$, where $\mathrm{x}=0$ is set at the tube supporting end (point $\mathrm{A}$ in Figure 4). Figure 14(a) and Figure 14(b) show the deformed contours of tubes inner wall expanded by cone pistons with different diameter of cylindrical part and length of tapered part, respectively. The black dotted line represents the contour of the inner wall of the initial tube. As shown in Figure 14(a), the solid line and the dotted line with the same color represent the expanded tubes and the cone piston of a certain expansion tube, respectively. It can be seen that both the plastic deformation of the tube and the gap between the expanded tube and the cylindrical part increases while the semi angle increases. As shown in Figure 14(b), when the semi angle $\alpha$ decreases, the gap between the expanded tube and the cylindrical part of the cone piston decreases. For example, the size of the gap is $0.991 \mathrm{~mm}$ when the semi angle equals to $26.57^{\circ}$, whereas the size of the gap is $0.242 \mathrm{~mm}$ when the semi angle equals to $7.58^{\circ}$. 


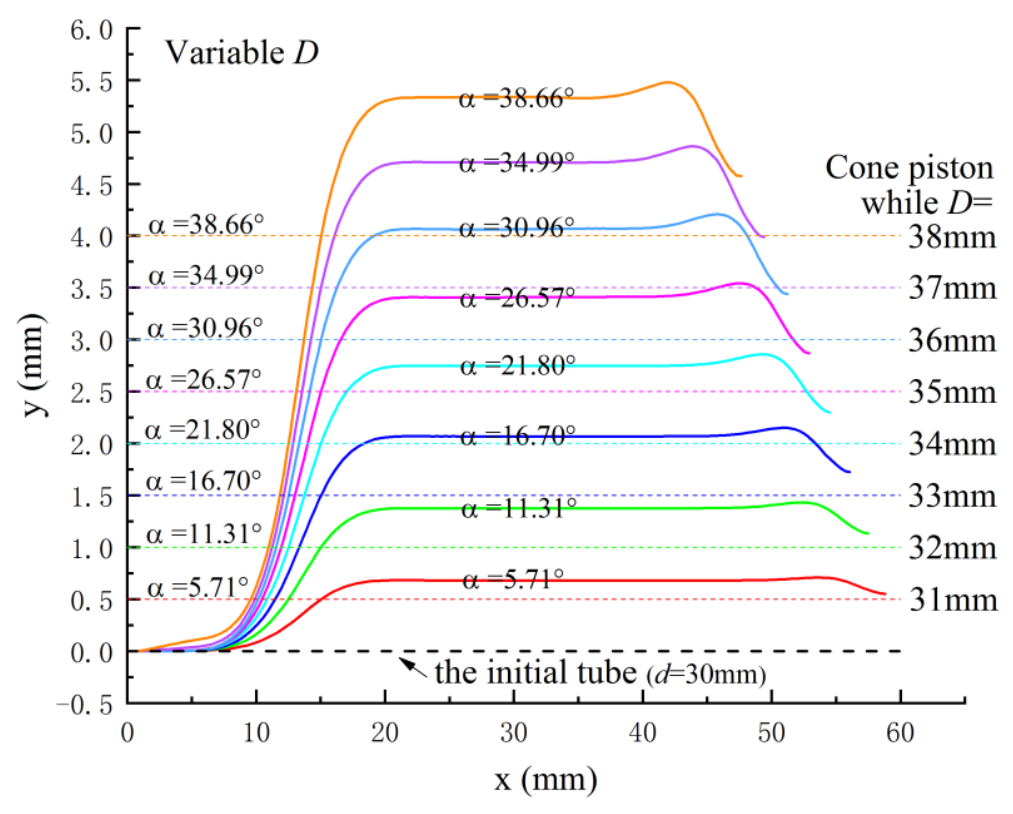

(a)

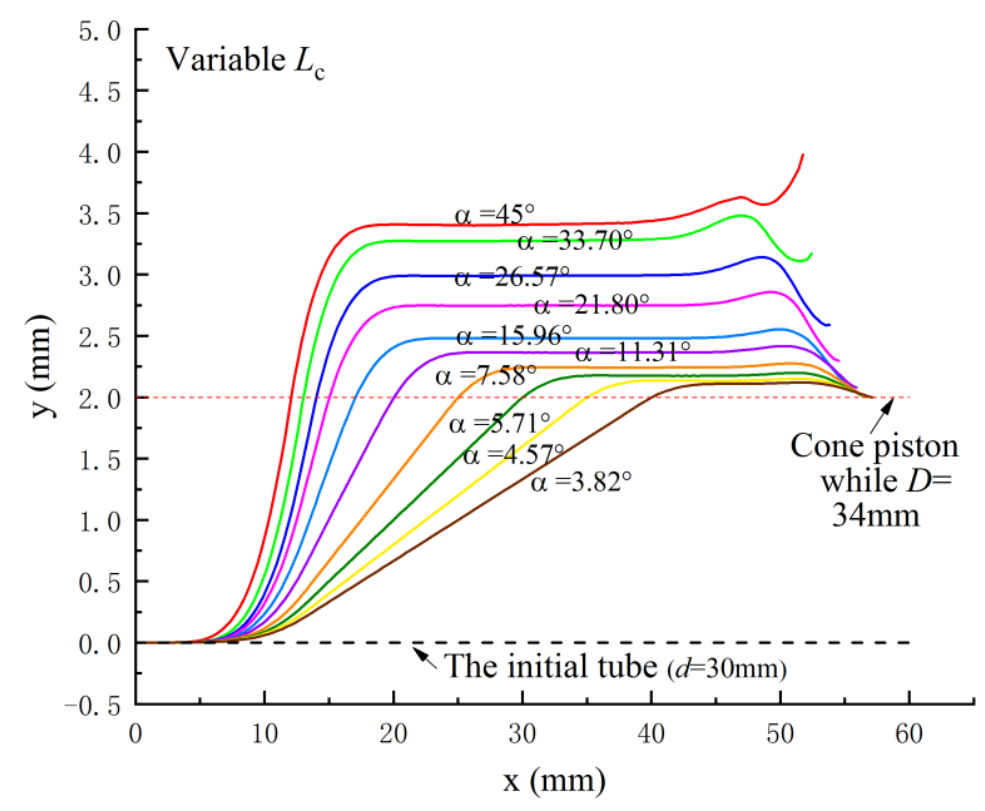

(b)

Figure 14. Plot of the configurations of the deformed tube from FE at successive semi angles of the cone piston, ranging from $3.82^{\circ}$ to $45^{\circ}: \mathrm{D}=34 \mathrm{~mm}, \mathrm{~S}=50 \mathrm{~mm}$. (y is the radial displacement of the tube and $\mathrm{x}$ is the distance from the rigid plate to the points on the inner wall of tube)

Figure 15 summarizes the amounts of energy absorbed by the plastic deformation of tube and the frictional dissipation when the displacement of cone piston $S=50 \mathrm{~mm}$. As shown in Figure 15(a), when the semi angle increases (with the increase of diameter of the cylindrical part), the plastic deformation energy increases significantly, whereas the frictional dissipation increases slowly. Hence, the total energy absorbed by the expansion tube increases with the increase of semi angle of cone piston. As shown in Figure 15(b), the total energy absorbed by the expansion tube did not increase significantly when the angle was less than $15.96^{\circ}$, which is caused by the changes in plastic deformation energy and frictional dissipation. When the semi angle increases, the plastic deformation energy increases significantly. However, the frictional dissipation decreases first, then the frictional dissipation maintains largely unchanged when the semi angle was more than $21.8^{\circ}$. 


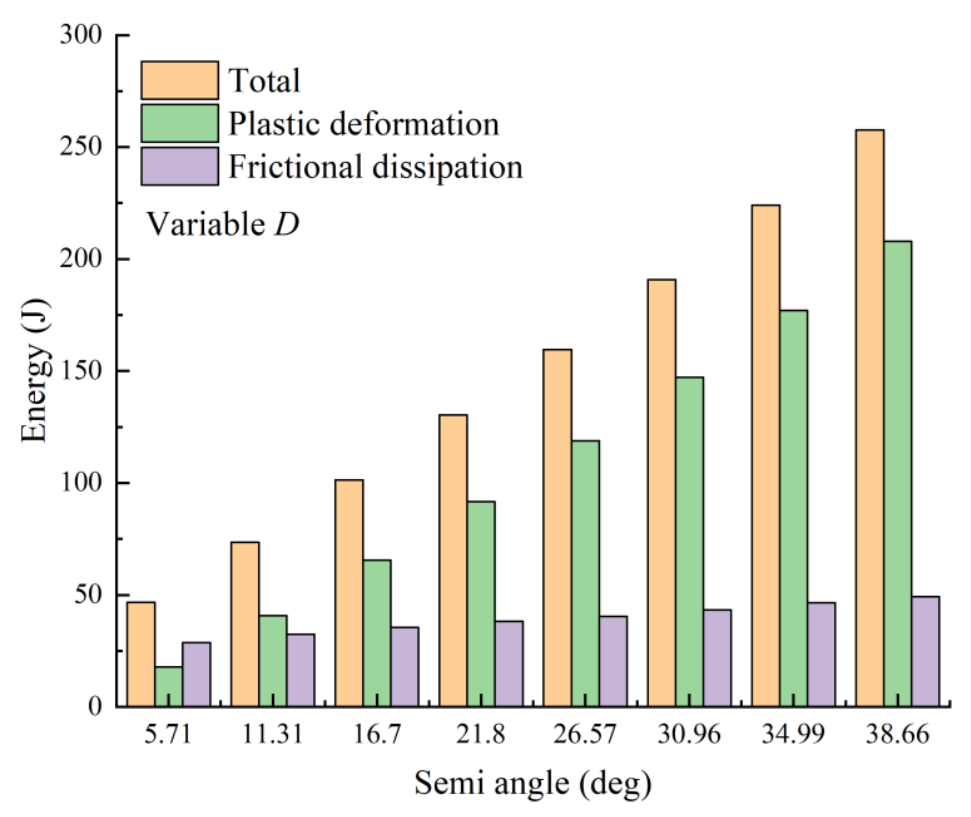

(a)

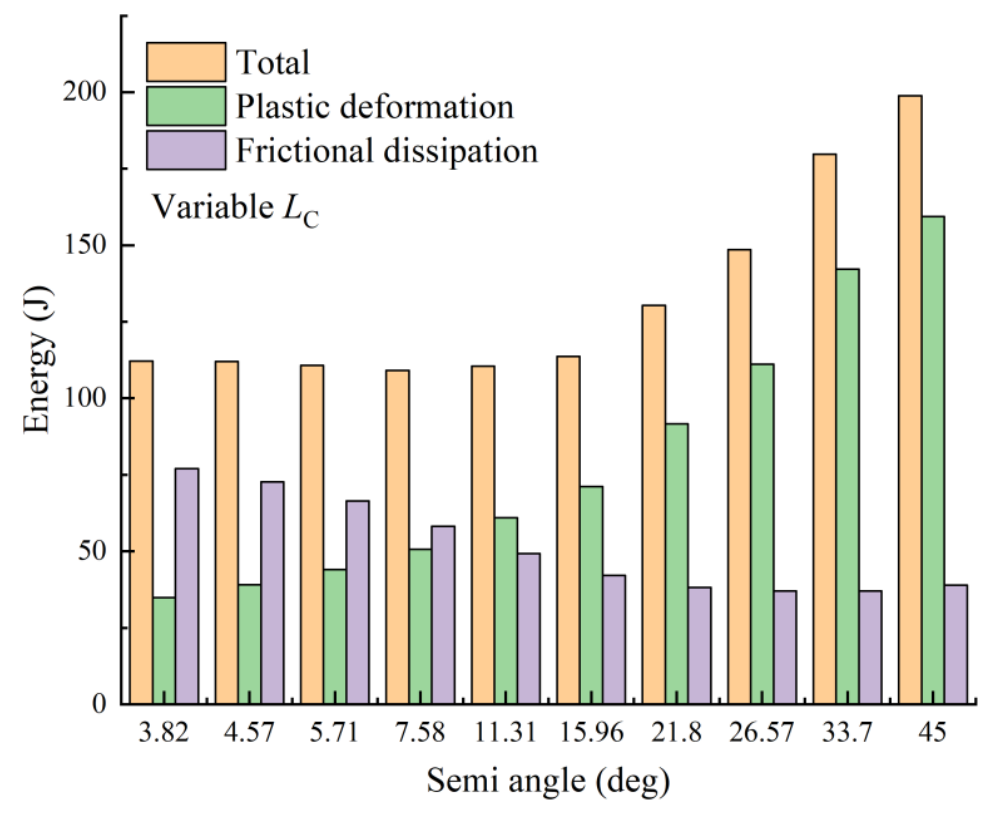

(b)

Figure 15. Energy distribution with respect to semi angle caused by: (a) variable diameters of the cylindrical part and (b) variable length of the tapered part of cone piston.

\subsubsection{Effect of tube material}

In order to investigate the material effect on the mechanical properties and energy absorption characteristics of tubes, different materials are used in the tube. The expansion force-displacement curves of the tubes with different materials is shown in Figure 16(a), and the stable-state expansion force tensile stress curve of tubes with different materials is shown in Figure 16(b). It can be seen that the trends of the expansion force-displacement curves are alike when the material of the tube changes. However, the stable-state expansion forces are different, i.e. the higher the tensile stress of the material is, the higher of the stable-state expansion force is. It should be noted that the value of stable- 
state expansion force is roughly linear with the tensile strength of tube material, rather than the yield strength.

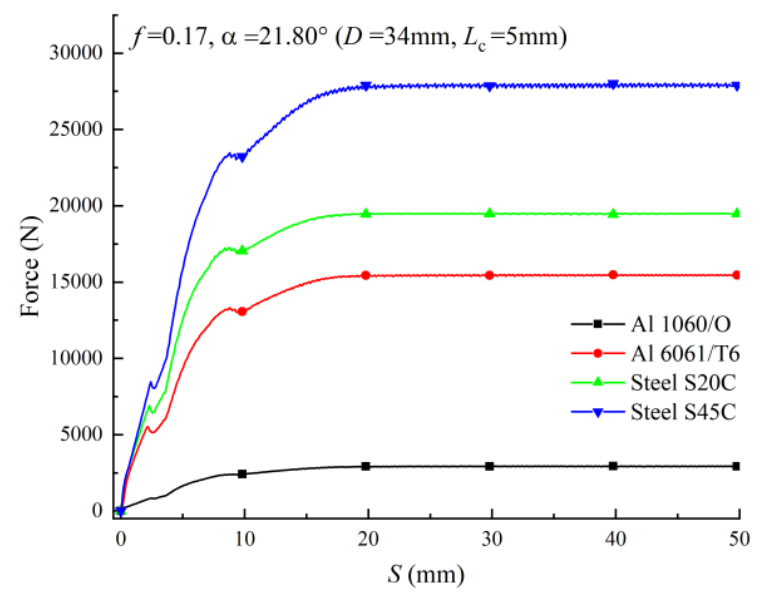

(a)

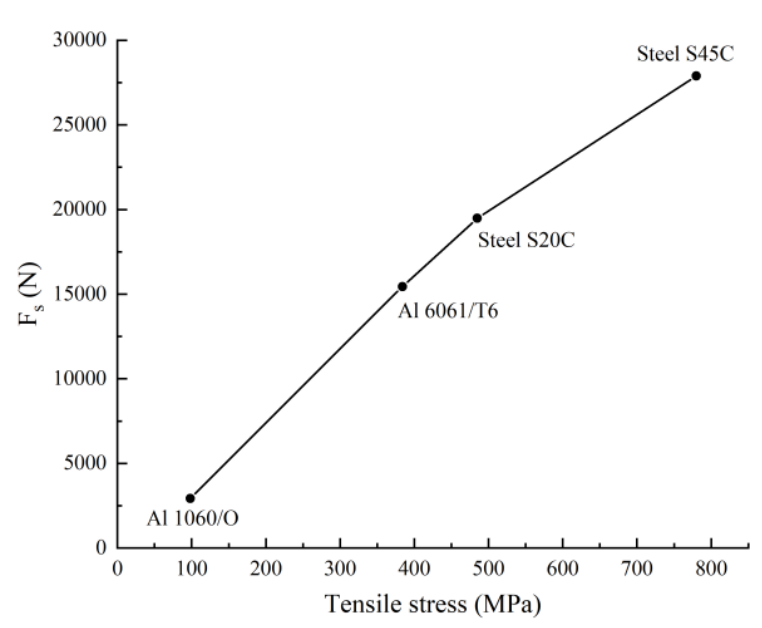

(b)

Figure 16. (a) Expansion force-displacement curves with respect to material, and (b) stable-state expansion force-tensile stress curve.

The composition percentage of the energy absorbed by expansion tubes of tubes with different material is listed in Table 5. It can be seen that the higher the tensile stress of tube material is, the more energy absorbed by the expansion tube. When the tensile stress of material increases, both the plastic energy and frictional energy increase. The contribution of each constituent factor of total energy absorption, i.e. plastic energy and frictional energy, against the tensile stress is shown in Figure 17. This figure suggests that the percentage of plastic energy and the percentage of frictional energy do not change when the parent material of tube changes.

Table 5. Summary of energy distribution of tubes with different parent materials.

\begin{tabular}{|c|c|c|c|c|c|}
\hline \multirow{2}{*}{$\begin{array}{l}\text { Tube } \\
\text { material }\end{array}$} & \multirow{2}{*}{$\begin{array}{l}\text { Tensile } \\
\text { stress/MPa }\end{array}$} & \multicolumn{3}{|c|}{ Energy absorption $(S=50 \mathrm{~mm})$} & \multirow{2}{*}{$W_{M} /(\mathbf{k J} / \mathbf{k g})$} \\
\hline & & Total /J & Plastic /J & Frictional /J & \\
\hline $\mathrm{Al} \mathrm{10601/O}$ & 98.2 & 130.29 & 91.68 & 38.26 & 4.80 \\
\hline Al 6061/T6 & 384.1 & 695.18 & 481.49 & 206.31 & 25.61 \\
\hline Steel S20C & 484.9 & 883.34 & 616.55 & 263.19 & 11.19 \\
\hline Steel S45C & 779.8 & 1240.11 & 868.15 & 362.29 & 15.71 \\
\hline
\end{tabular}




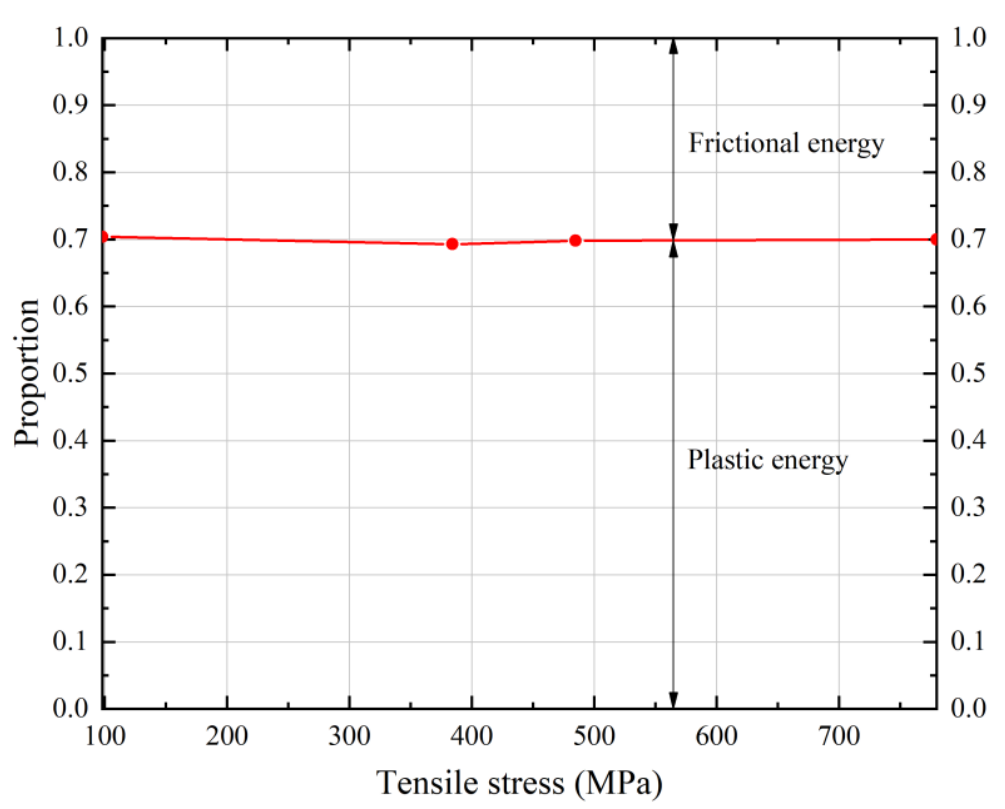

Figure 17. Partition of two energy components with respect of tensile stress.

To evaluate the energy absorption capacity per unit mass of the expansion tubes with different tube materials, specific energy absorption $W_{\mathrm{M}}$ was proposed. $W_{\mathrm{M}}$ is defined as:

$$
W_{M}=\frac{W}{m}=\frac{\int_{0}^{L} F(S) d S}{\rho L \pi(d+t) t}
$$

where $\mathrm{W}$ is the total energy absorption, whose value equals to the integral area between the expansion force-curve and the displacement coordinate. $L$ is the displacement of the cone piston, which is $50 \mathrm{~mm}$ here. $F(S)$ represents the expansion force during the process of energy absorption. The density $\rho$ of tube material is listed in Table 1 and Table 3 , and $m$ is the mass of the $50 \mathrm{~mm}$ long tube.

These values of $W_{\mathrm{M}}$ are listed in Table 5. It can be seen that the expansion tubes of different tube materials have significantly different specific energy absorption. Although the total energy absorption of steel S45C is larger than that of $\mathrm{Al} \mathrm{6061/T6,} \mathrm{the} \mathrm{specific} \mathrm{energy} \mathrm{absorption} \mathrm{of} \mathrm{steel} \mathrm{S45C}$ is smaller than that of $\mathrm{Al} \mathrm{6061/T6,} \mathrm{which} \mathrm{is} \mathrm{owing} \mathrm{to} \mathrm{the} \mathrm{density} \mathrm{of} \mathrm{steel} \mathrm{S45C} \mathrm{much} \mathrm{bigger} \mathrm{than} \mathrm{Al}$ 6061/T6. For tube materials with the same density (i.e. S20C and S45C), the larger the tensile stress is, the specific energy absorption $W_{\mathrm{M}}$ is. Figure 18 shows the relationship between the specific energy absorption and tensile stress/density of tube material at displacement of $S=20 \mathrm{~mm}$ (approximately reaching the stable-state stage II), $S=35 \mathrm{~mm}, S=35 \mathrm{~mm}$. The points present the specific energy absorption $W_{\mathrm{M}}$ of material at a certain displacement, and the lines are obtained by fitting the $W_{\mathrm{M}}$ of four different materials at the same displacement. It can be seen that the specific energy absorption $W_{\mathrm{M}}$ is approximately linear with the tensile stress/density $\left(\sigma_{\mathrm{b}} / \rho\right)$ of tube material. The larger the tensile stress/density of tube material is, the larger the specific energy absorption is, which demonstrates that the lightweight and high-strength materials have larger specific energy absorption. Comparing the lines shown in Figure 18, the slope of the lines increase with the increase of displacement of cone piston, namely, the specific energy absorption increases as the increase of displacement of cone piston. It can be concluded that the larger the tensile stress/density of tube material and the displacement of cone piston are, the larger the specific energy absorption is. 


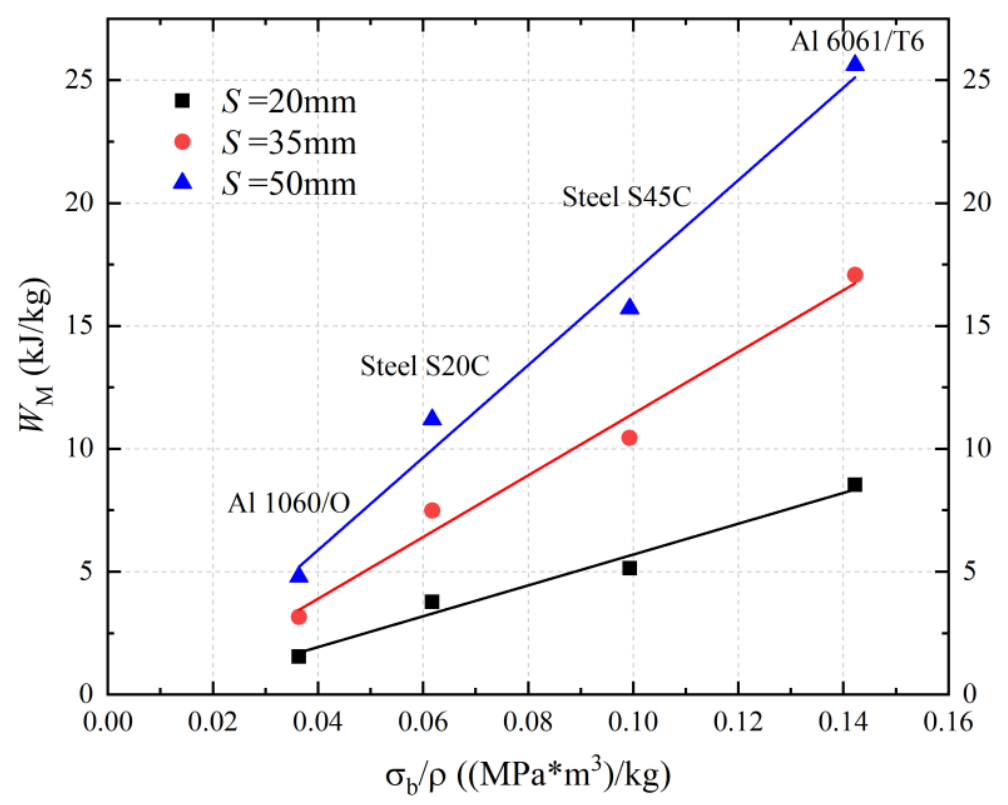

Figure 18. Relationship between the specific energy absorption $W_{\mathrm{M}}$ and tensile stress/density of tube material $\left(\sigma_{b} / \rho\right)$ with respect to displacement of cone piston.

\subsubsection{Effect of friction coefficient}

To evaluate the effect of friction coefficient on the mechanical response of expansion tube, different contact conditions with different friction coefficients were calculated. Figure 19(a) shows the expansion force-displacement curves with varies friction coefficients, and Figure 19(b) shows the stable-state expansion force $\left(\mathrm{F}_{\mathrm{s}}\right)$-friction coefficient $(f)$ curve. It can be seen that the stable-state expansion force increases linearly when the friction coefficient increases.

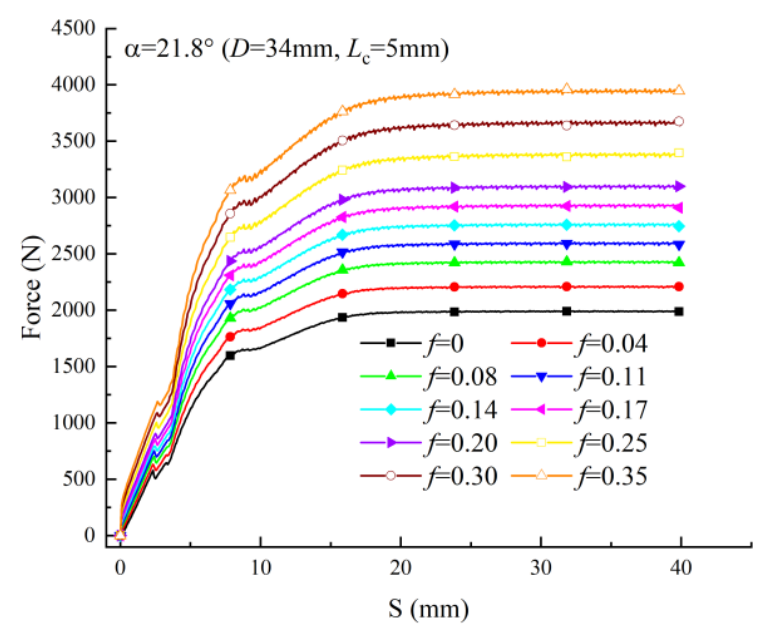

(a)

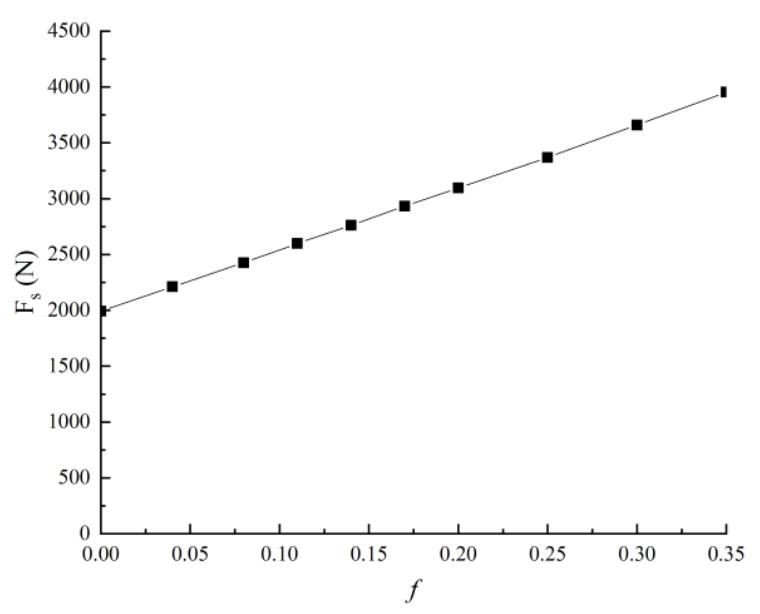

(b)

Figure 19. (a) Expansion force-displacement curves with multiple friction coefficient, and (b) stablestate expansion force-friction coefficient curve.

Table 6 lists the energy absorbed by expansion tubes $\left(\alpha=21.8^{\circ}, D=34 \mathrm{~mm}, L_{c}=5 \mathrm{~mm}\right)$ with different friction coefficients when the displacement of cone piston is $50 \mathrm{~mm}$. Figure 20 shows the trend of total energy, plastic deformation energy and frictional dissipation energy with the change of friction coefficient. It indicates that the total energy absorbed by expansion tubes increases considerably and almost linearly with respect to friction coefficient. The specific energy absorption increases with the increase of friction coefficient. Actually, this is owing to the increase of both plastic deformation and frictional dissipation. The energy of frictional dissipation increases significantly, and the energy of 
plastic deformation changes slightly with the increase of friction coefficient. The slight changes of plastic deformation energy is because of the extra shear transformation brought by friction [18], which will hinder the flow of the inner wall metal of the tube. When the friction coefficient is 0.17 , the energy absorbed by unit length of expansion tube is $2.61 \mathrm{~J} / \mathrm{mm}$. Additionally, the energy used to overcome the plastic deformation and frictional dissipation is about $70.37 \%$ and $29.37 \%$ of the total energy absorbed by expansion tube in case of $f=0.17$.

Table 6. Summary of energy distribution under different contact conditions.

\begin{tabular}{|c|c|c|c|c|c|c|c|}
\hline \multirow[b]{2}{*}{$\begin{array}{l}\text { Friction } \\
\text { coefficient }\end{array}$} & \multicolumn{2}{|c|}{ Total absorption } & \multicolumn{2}{|c|}{ Plastic deformation } & \multicolumn{2}{|c|}{ Friction dissipation } & \multirow[b]{2}{*}{$\begin{array}{l}W_{\mathrm{M}} /(\mathrm{kJ} / \\
\mathrm{kg})\end{array}$} \\
\hline & $\begin{array}{c}\text { Energy } \\
/ / J\end{array}$ & $\begin{array}{l}\text { Unit length } \\
\text { absorption } \\
/(\mathrm{J} / \mathrm{mm})\end{array}$ & $\begin{array}{c}\text { Energy } \\
/ / J\end{array}$ & $\begin{array}{c}\text { Proportion } \\
/ \%\end{array}$ & $\begin{array}{c}\text { Energy } \\
\text { /J }\end{array}$ & $\begin{array}{c}\text { Proportion } \\
/ \%\end{array}$ & \\
\hline$f=0$ & 89.69 & 1.79 & 89.34 & 99.61 & 0 & 0.00 & 3.30 \\
\hline$f=0.04$ & 98.96 & 1.98 & 89.75 & 90.69 & 8.86 & 8.95 & 3.65 \\
\hline$f=0.08$ & 108.37 & 2.17 & 90.24 & 83.27 & 17.78 & 16.41 & 3.99 \\
\hline$f=0.11$ & 115.49 & 2.31 & 90.64 & 78.48 & 24.50 & 21.21 & 4.25 \\
\hline$f=0.14$ & 122.80 & 2.46 & 91.12 & 74.20 & 31.33 & 25.51 & 4.52 \\
\hline$f=0.17$ & 130.29 & 2.61 & 91.68 & 70.37 & 38.26 & 29.37 & 4.80 \\
\hline$f=0.20$ & 137.55 & 2.75 & 92.26 & 67.07 & 44.94 & 32.67 & 5.07 \\
\hline$f=0.25$ & 148.80 & 2.98 & 93.24 & 62.66 & 55.21 & 37.10 & 5.48 \\
\hline$f=0.30$ & 160.75 & 3.22 & 94.39 & 58.72 & 66.00 & 41.06 & 5.92 \\
\hline$f=0.35$ & 173.05 & 3.46 & 95.65 & 55.27 & 77.04 & 44.52 & 6.38 \\
\hline
\end{tabular}

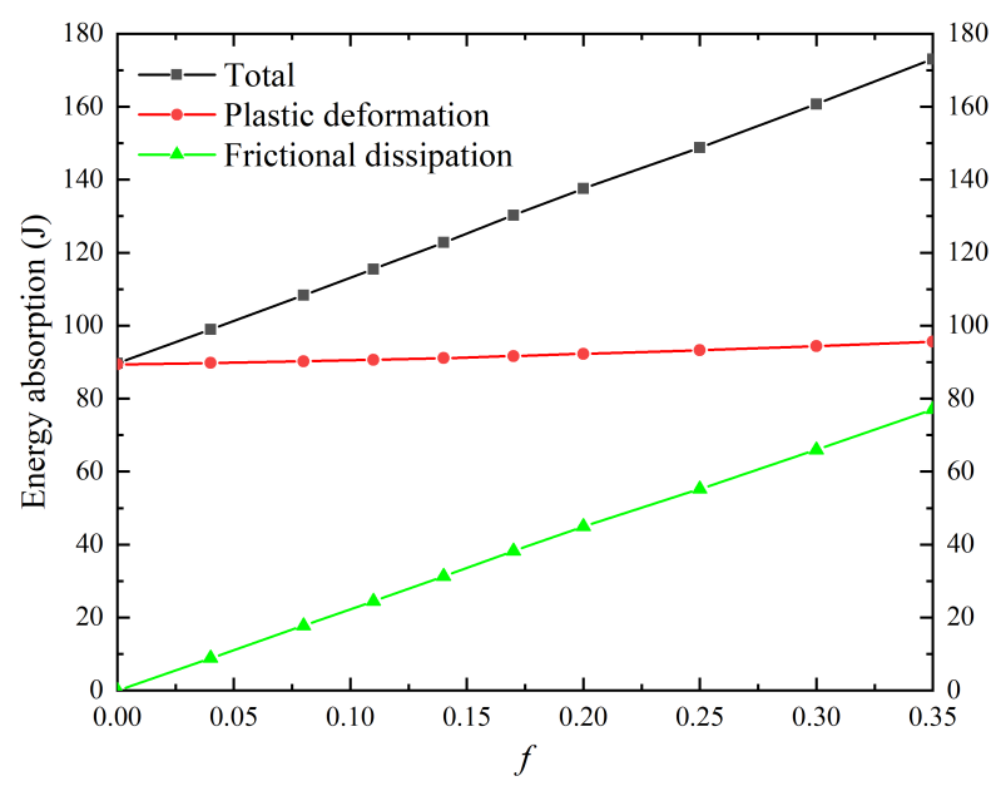

Figure 20. Variation of the total energy, plastic deformation energy and friction dissipation energy with respect to friction coefficient.

\section{Conclusions}

The mechanical response and energy absorption characteristics of expansion tube have been investigated, particularly the effect of semi angle of cone piston, friction coefficient and tube parent material. A series of finite element simulations of tube expansion were conducted using commercial software ABAQUS to facilitate the interpretation of the process of tube expansion and study the distribution of absorbed energy. The experiments were also conducted to validate the finite element model. The validated finite element simulation matched the experimental measurements reasonably. Conclusions can be drawn as follows

(1) The stable-state expansion force increases with the increase of semi angle by changing the diameter of cylindrical part. However, the stable-state expansion force decreases first and then 
increases when the semi angle increases by changing the length of tapered part, thus there is a minimum stable-state expansion force when the semi angle in the range of $11.31^{\circ}-21.80^{\circ}$ by changing the tapered part length. As for the energy of plastic deformation, it increases significantly when the semi angle increases by changing the diameter of cylindrical part. However, when the semi angle is less than $15.96^{\circ}$, the energy of plastic deformation does not increase significantly as the semi angle increases by changing the length of tapered part.

(2) The composition percentage of absorbed energy basically unchanged with the change of tube material. However, the specific energy absorption of expansion tube is linear with the tensile stress/density of the parent material

(3) The stable-state expansion force, frictional energy and energy absorption capacity increase linearly with the increase of friction coefficient. However, the plastic energy increase slowly owing to the extra shear transformation.

In the current study, the tubes are expanded only under quasi-static loading condition. The mechanical response of tube expansion under dynamic impact will be studied in the future work.

Author Contributions: Conceptualization, Z.Q.; methodology, Y.L. and Y.Z.; software, Z.Q.; validation, Z.Q., Y.Z. and Y.L.; formal analysis, Z.Q.; investigation, Z.Q.; resources, Y.L. and Y.Z.; data curation, Z.Q.; writingoriginal draft preparation, Z.Q.; writing - review and editing, Z.Q., Y.Z. and Y.L.; visualization, Z.Q., and Y.Z.; supervision, Y.L. and Y.Z.; project administration, Y.L.; funding acquisition, Y.L. All authors have read and agreed to the published version of the manuscript.

Funding: This research was funded by the National Natural Science Foundation of China (Grant number 11672329).

Acknowledgments: This work was supported in part by the Foundation of National University of Defense Technology.

Conflicts of Interest: The authors declare no conflict of interest.

\section{References}

1. Nurick, G. N.; Shave, G. C., The deformation and tearing of thin square plates subjected to impulsive loads-An experimental study. International Journal of Impact Engineering 18, (1), 99-116.

2. Stronge, W. J.; Yu, T. X.; Johnson, W., Long stroke energy dissipation in splitting tubes. International Journal of Mechanical Sciences 1983, 25, (9), 637-647.

3. Reid, S. R., Plastic deformation mechanisms in axially compressed metal tubes used as impact energy absorbers. International Journal of Mechanical Sciences 1993, 35, (12), 1035-1052.

4. Langseth, M.; Hopperstad, O. S.; Hanssen, A. G., Crash behaviour of thin-walled aluminium members. Thin-Walled Structures 1998, 32, (1), 127-150.

5. Almeida, B. P. P.; Alves, M. L.; Rosa, P. A. R.; Brito, A. G.; Martins, P. A. F., Expansion and reduction of thin-walled tubes using a die: Experimental and theoretical investigation. International Journal of Machine Tools and Manufacture 2006, (12-13), 1643.

6. Shakeri, M.; Salehghaffari, S.; Mirzaeifar, R., Expansion of circular tubes by rigid tubes as impact energy absorbers: experimental and theoretical investigation. International Journal of Crashworthiness 2007, 12, (5), 493-501.

7. Zhang, X.; Cheng, G., A comparative study of energy absorption characteristics of foam-filled and multi-cell square columns. International Journal of Impact Engineering 2007, 34, (11), 1739-1752.

8. Guillow, S. R.; Lu, G.; Grzebieta, R. H., Quasi-static Axial Compression of Thin-Walled Circular Aluminium Tubes. International Journal of Mechanical Sciences 2001, 43, (9), 2103-2123.

9. Zhang, X.; Zhang, H.; Wen, Z., Axial crushing of tapered circular tubes with graded thickness. International Journal of Mechanical Sciences 2015, 92, 12-23. 
10. Reddy, T. Y.; Reid, S. R., Axial splitting of circular metal tubes. International Journal of Mechanical Sciences 1986, 28, (2), 111-131.

11. Huang, X.; Lu, G.; Yu, T. X., On the axial splitting and curling of circular metal tubes. International Journal of Mechanical Sciences 2002.

12. Choi, W. M.; Kim, J. S.; Jung, H. S.; Kwon, T. S., Effect of punch angle on energy absorbing characteristics of tube-type crash elements. International Journal of Automotive Technology 2011, 12, (3), 383-389.

13. Choi, W. M.; Kwon, T. S.; Jung, H. S.; Kim, J. S., Influence of impact velocity on energy absorption characteristics and friction coefficient of expansion tube. International Journal of Crashworthiness 2012, 17, (6), 621-629.

14. Qi, Z.; Zhang, Y.; Lin, Y.; Chen, R.; Meng, Y., Dynamic Response and Energy Absorption Characteristics of Expansion Tubes Under Axial Impact. IEEE Access 2020, 8, 90528-90541.

15. Liu, H.; Zhang, X.; Luo, A. In Expansion tubes as impact energy absorbers: Experimental investigations and numerical simulations, 2017 IEEE International Conference on Mechatronics and Automation (ICMA), 69 Aug. 2017, 2017; pp 1366-1371.

16. Yang, J.; Luo, M.; Hua, Y.; Lu, G., Energy absorption of expansion tubes using a conical-cylindrical die: Experiments and numerical simulation. International Journal of Mechanical Sciences 2010, 52, (5), 716-725.

17. Mahmoodi, A.; Shojaeefard, M. H.; Saeidi Googarchin, H., Theoretical development and numerical investigation on energy absorption behavior of tapered multi-cell tubes. Thin-Walled Structures 2016, 102, 98-110.

18. Yan, J.; Yao, S.; Xu, P.; Peng, Y.; Shao, H.; Zhao, S., Theoretical prediction and numerical studies of expanding circular tubes as energy absorbers. International Journal of Mechanical Sciences 2016, 105, 206214.

19. Liu, Q.; Wang, W.-t.; Zhang, W.-f., Study on buffering performance of thin-walled metal tube with different angles. Defence Technology 2018.

20. Zhang, Y.; Liu, T.; Tizani, W., Experimental and numerical analysis of dynamic compressive response of Nomex honeycombs. Composites Part B: Engineering 2018, 148, 27-39.

21. Fischer, F. D.; Rammerstorfer, F. G.; Daxner, T., Flaring-An analytical approach. International Journal of Mechanical Sciences 2006, 48, (11), 1246-1255.

22. Alves, M. L.; Almeida, B. P. P.; Rosa, P. A. R.; Martins, P. A. F., End forming of thin-walled tubes. Journal of Materials Processing Tech. 2006, 177, (1-3), 183-187.

23. Alves, L. M.; Martins, P. A. F., Cold expansion and reduction of thin-walled PVC tubes using a die. Journal of Materials Processing Technology 2009, 209, (9), 4229-4236.

24. Li, X.; Lin, Y.; Lu, F.; Zhang, Y., Quasi-static cutting response of combined hexagonal aluminium honeycombs at various stacking angles. Composite Structures 2020, 238, 111942.

25. Zhang, Y.; Wang, S.; Yan, L., Transverse compressive characteristics of fiber reinforced cementitious composites tubes. Thin-Walled Structures 2020, 150, 106645.

26. Zhang, Y.; Liu, T.; Xu, Z., Dynamic response of hybrid carbon fibre laminate beams under ballistic impact. Composite Structures 2019, 210, 409-420.

27. ABAQUS, ABAQUS analysis user's manual, Version 6.14. ABAQUS, Inc 2014.

28. Liu, Y.; Qiu, X., A theoretical study of the expansion metal tubes. International Journal of Mechanical Sciences 2016, 114, 157-165.

29. Qin, J.; Chen, R.; Wen, X.; Lin, Y.; Liang, M.; Lu, F., Mechanical behaviour of dual-phase high-strength steel under high strain rate tensile loading. Materials Science \& Engineering A 2013, 586, (dec.1), 62-70. 
30. Zhang, Y.; Liu, T.; Ren, H.; Maskery, I.; Ashcroft, I., Dynamic compressive response of additively manufactured AlSi10Mg alloy hierarchical honeycomb structures. Composite Structures 2018, 195, 45-59. 